\section{Surveying Writ Large}

Geodesy. By G. Bomford. Third edition. Pp. $\mathrm{x}+731$. (Clarendon: Oxford; Oxford University: London, January 1971.) $£ 10.00$.

How does one review the third revised edition of the standard reference tome on geodesy? It is quite impossible, of course, if only because this book "aims at covering the whole field of geodesy". In any case this is not the sort of book one takes to bed for a light read; and specialists familiar with the first and second editions will already know what they want to know about the quality of this work. I shall, therefore, concentrate on what I presume readers of this review will want to know most-how this new edition of Bomford's tome differs from the previous ones.

In fact, the textural changes are quite extensive. What Bomford would have thought of at the time of the second edition (1962) as "novelties"-electromagnetic distance measurement, electronic computers, artificial satellites and the like-have revolutionized methods of geodetic observation during the past decade. In other words, new technological developments have altered the whole basis of geodesy as much as pushing back the frontiers of knowledge. Thus the traverse is now taken as having more or less superseded triangulation for new geodetic frameworks; and because electromagnetic methods are now important so are such side issues as the effects of meteorology on the velocity of electromagnetic waves. The advantages of the computer for a subject which deals with vast masses of repetitive data are, of course, obvious. And perhaps the main reason for the increased quantity of data available is the satellite. Bomford notes, however, that satellite geodesy has become such a large and expanding subject that it is not possible to give a comprehensive treatment even in a tome.

Geodesy is, of course, two things which overlap not a little-the basis of surveying and the source of important geophysical data. There is a large area of blurred definitions here; but in so far as the two aspects of geodesy are distinguishable, Bomford tends to fight shy of the geophysical. For this reason his book will be of less interest to geophysicists than it might have been, though it is not quite as black and white as that. For example, absent from the first edition but present in the third is a brief treatment of Earth tides which forms part of a much longer chapter on physical geodesy - a chapter which incidentally tends to linger over the mathematical aspects of the subject. The geophysicist interested in the physical principles involved will, however, find more satisfactory treatments elsewhere. For geodesy as super-surveying, though, Bomford's tome is essential.

Peter J. Smith

\section{Survey of Sediments}

Ancient Sedimentary Environments : a Brief Survey. By Richard C. Selley. Pp. xiv +237. (Chapman and Hall: London, January 1971.) $£ 2.25$.

THERE is much to be said for a book which explains ideas within a particular field in terms of "case histories" of research work and in a manner which students can readily assimilate. On the basis of the uniformitarianism principle, the author has taken ten discrete sedimentary environments and, by analogy with present-day conditions, has attempted to show how an analysis of environment may be carried out from the sediments. Following a brief introduction to environments and facies, in which the parameters and indicators of environment are touched on, each of the environments is studied in turnriver, windblown and lake deposits, deltas and shoreline deposits, reefs, flysch, and pelagic deposits.

First, characteristics of the environment existing at the present day are set down, and this account is followed by a description of an example from the stratigraphic column deposited under similar conditions. The procedures for interpretation and analysis of the "ancient" environment are then discussed, and finally a short economic assessment of the environment is given. In so doing, the book demonstrates methods by example and hence much is to be learned from a study of it. Also, because the author has used the accounts of other workers for his "case histories", a wider outlook on the subject is achieved, for there is a pool of experience from which to draw. A short chapter is included on the mathematical approaches to analysis, and the summary of environmental characteristics at the end of the book is particularly useful.

Because the organization and content of the book are so suited to beginners in the subject, it is all the more a pity that the style is disjointed. There are too many unlinked statements and successions of short staccato sentences which, while in no way detracting from the scholarship of the book, do tend to mar its clarity. Diagrams are neatly executed and all stratigraphic sections follow a standard key. Inconsistencies do occur, however, and the construction of the standard key might have been better explained. The diagrams attempting to show three dimensional representations of facies at the end of the book fail lamentably; not only are the axes shown unconventionally but there is no way of discerning into which plane, or octant, the data indicated fall.

The fact that "the oil industry refuses to go metric" is no excuse to be unscientific, and the indiscriminate use of metres and feet further suggests a lack of attention to detail. JoHN Brooks

\section{Elasticity for Engineers}

Large Elastic Deformations. By A. E. Green and J. E. Adkins. Second edition, revised by A. E. Green. Pp. xiv + 324. (Clarendon: Oxford ; Oxford University: London, December 1970.) $£ 4.75$.

IN the intervening years between the appearance of the first edition of the book and this revised text, engineers and other applied scientists have been faced with an increasing number of problems which involve large elastic displacement behaviour. This type of behaviour can arise either from the nature of the component material, for example plastics, or from the geometrical configuration of the system as encountered in shell structure design. It is also possible to have both material and geometrical configuration effects as in the case of large inflatable membrane structures. The complete analysis of large elastic deformation systems is complex and is not adequately catered for by the usual engineering theories of component and system behaviour. The more mathematically sophisticated analytical techniques required for the complete analysis of such problems are better understood by the professional mathematician. The present text, which discusses these problems, is most suited to such a person.

In more detail, this book, which for a clear understanding is dependent on the early chapters of Theoretical Elasticity by A. E. Green and W. Zerna, is very much the same as the first edition, with the deletion of the chapters on stability and the rheological equations of state. These subjects are omitted because of the rapid advances made during the last decade, which demand a fuller exposition in another text. Some corrections have been made to chapter II and there is an additional section on the initially curved cuboid. Also chapter VIII on thermo-elasticity has been rewritten in a way more compatible with the present state of the subject. A few additional references have been included throughout the book, keeping the reader up to date with developments in those aspects of the subject which have been covered.

The book again has a high standard of accuracy and clarity of presentation and will remain an excellent standard text on finite elastic deformation.

M. M. BlaCK

H. M. Semple 